\title{
Autologous stromal vascular fraction cells combined with platelet-rich plasma for androgenic alopecia treatment: a
}

\section{case series [version 1; peer review: 2 approved with}

\section{reservations]}

\author{
Fonny Josh (Did1,2, Tomie Hermawan Soekamto (iD)3, Muhammad Faruk (iD) \\ ${ }^{1}$ Division of Plastic and Reconstructive Surgery, Department of Surgery, Faculty of Medicine, Hasanuddin University, Makassar, \\ South Sulawesi, 90245, Indonesia \\ ${ }^{2}$ Division of Plastic and Reconstructive Surgery, Department of Surgery, Dr Wahidin Sudirohusodo Hospital, Makassar, South \\ Sulawesi, 90245, Indonesia \\ ${ }^{3}$ Department of Plastic and Reconstructive Surgery, Koja Hospital, Jakarta, 14220, Indonesia \\ ${ }^{4}$ Department of Surgery, Faculty of Medicine, Hasanuddin University, Makassar, South Sulawesi, 90245, Indonesia
}

V1 First published: 20 May 2021, 10:408

https://doi.org/10.12688/f1000research.52712.1

Latest published: 20 May 2021, 10:408

https://doi.org/10.12688/f1000research.52712.1

\section{Abstract}

Background: Stromal vascular fraction cells (SVFs), which can be produced using a mechanical or digestive enzymatic process, are heterogeneous cells with the potential to grow hair in androgenic alopecia patients. Platelet-rich plasma (PRP) is an autologous cell source that is widely used to treat androgenic alopecia. However, the combined use of PRP and SVFs to treat alopecia is rarely reported. Case presentation: This case series describes three cases of androgenic alopecia, including a32-year-old male, a 43-year-old male, and a 65-year-old male. Androgenic alopecia in these patients was treated by injecting the bald area of the scalp with local autologous PRP combined with SVFs. Follow-up was performed 1-3 months after treatment, which showed good results. The hair grew denser, with increased thickness for each strand. The hair pull test revealed that the hair remained intact.

Conclusion: The combination of PRP and SVFs affected all cycles of the hair growth process. SVFs are multipotent cells with the potential to become antioxidant, anti-inflammatory, or anti-fibrotic cells. SVFs can regenerate cells that secrete the growth factors, that are essential for angiogenesis, which can improve therapeutic outcomes. This case series will enrich the existing literature by expanding available treatment options for androgenic alopecia.

\section{Keywords}

Androgenic alopecia, Stem cell therapy, Stromal vascular fraction cells, Platelet-rich plasma.

\section{Open Peer Review}

Approval Status? ?

12

version $1 ?$ ?

20 May $2021 \quad$ view view

1. Hiroshi Mizuno, Juntendo University School of Medicine, Tokyo, Japan

2. Dewi Sukmawati ID, Universitas Indonesia, Jakarta, Indonesia

Any reports and responses or comments on the article can be found at the end of the article. 
Corresponding author: Fonny Josh (fonnyjosh2003@yahoo.com)

Author roles: Josh F: Conceptualization, Data Curation, Formal Analysis, Funding Acquisition, Investigation, Methodology, Resources, Supervision, Visualization, Writing - Original Draft Preparation, Writing - Review \& Editing; Soekamto TH: Conceptualization, Data Curation, Formal Analysis, Funding Acquisition, Investigation, Methodology, Resources, Supervision, Validation, Visualization, Writing Original Draft Preparation, Writing - Review \& Editing; Faruk M: Conceptualization, Data Curation, Formal Analysis, Investigation, Project Administration, Resources, Software, Validation, Visualization, Writing - Review \& Editing

Competing interests: No competing interests were disclosed.

Grant information: The author(s) declared that no grants were involved in supporting this work.

Copyright: ( $\odot 2021$ Josh F et al. This is an open access article distributed under the terms of the Creative Commons Attribution License, which permits unrestricted use, distribution, and reproduction in any medium, provided the original work is properly cited.

How to cite this article: Josh F, Soekamto TH and Faruk M. Autologous stromal vascular fraction cells combined with platelet-rich plasma for androgenic alopecia treatment: a case series [version 1; peer review: 2 approved with reservations] F1000Research 2021, 10:408 https://doi.org/10.12688/f1000research.52712.1

First published: 20 May 2021, 10:408 https://doi.org/10.12688/f1000research.52712.1 


\section{Introduction}

Androgenic alopecia, also known as androgenetic alopecia, male pattern baldness, and common baldness, represents a common form of hair loss that affects both men and women. ${ }^{1}$ Although the incidence rate of androgenic alopecia is $50 \%$ higher in men than in women, approximately $13 \%$ of premenopausal women suffer from androgenic alopecia, and the incidence increases significantly after menopause. ${ }^{2}$ In men, androgenic alopecia is typically hereditary and is strongly associated with low androgen hormone levels. A genetic process that links the 3q26 locus with the X chromosome can result in the development of androgenic alopecia in women. ${ }^{3}$ The accelerated conversion of testosterone to its derivate dihydrotestosterone (DHT) can also cause androgenic alopecia. This conversion of testosterone to DHT typically begins soon after the end of puberty, at approximately 20 years of age. DHT induces the production of a type II enzyme called 5- $\alpha$ reductase. Hair follicles that are exposed to DHT become weak and incapable of growing healthy hair strands, resulting in a shorter anagen phase, a more prolonged telogen phase, and hair follicle shrinkage. ${ }^{4}$ Although androgenic alopecia appears to be a mild condition, patients with an androgenic alopecia can become unhappy with their appearance, resulting in anxiety, depression, and reduced self-confidence.

Platelet-rich plasma (PRP) refers to concentrated platelets in a small plasma volume, which typically contains at least six essential growth factors, including platelet-derived growth factor (PDGF), basic fibroblast growth factor (bFGF), epidermal growth factor (EGF), vascular endothelial growth factor (VEGF), insulin-like growth factor-1 (IGF-1), and transforming growth factor- $\beta$ (TGF- $\beta$ ). Platelet activation can stimulate the release of these growth factors. Studies have demonstrated the positive effects of PRP on undifferentiated stem cells, promoting angiogenesis and proliferation, and the stimulation of both undifferentiated and differentiated stem cells with PRP can promote cell regeneration. ${ }^{5-7}$

Adipose cells contain multipotent progenitor cells, which are capable of self-renewal and differentiation into several different cell types. Adipose-derived stem cells (ADSCs) are stem cells obtained from fat and have been widely used to accelerate the wound-healing process and promote cell regeneration. ${ }^{8}$ However, the processing necessary to obtain ADSCs can be complex. ADSCs require a good fat harvesting method, a suitable isolation procedure, and an appropriate culturing process, which all require access to excellent laboratory facilities. Stromal vascular fraction cells (SVFs) are a non-expanded version of ADSCs that contain several heterogeneous cell types, including hematopoietic stem cells, endothelial progenitor cells, and ADSCs, which allow for SVFs to differentiating into several cell types. ${ }^{9,10}$ Although the interactions between SVFs and PRP remain unclear, several experiments have explored the effects of combining these treatments. The combinations of SVFs and PRP in cultured medium has demonstrated vigorous proliferation activity compared with that in basal medium. ${ }^{11}$ The collection of SVFs utilizes simpler fat harvesting and isolation processes compared with the collection of ADSCs. For example, SVFs do not require a culturing process, and because SVFs contain ADSCs, SVFs retain a multipotent characteristic and the ability to secrete several growth factors.

In this case series, we describe the combined use of PRP with SVFs to support hair regeneration in three patients, with the aim of supplying a larger population of growth factors than can be found in either PRP or SVFs alone. SVFs were used to treat androgenic alopecia due to the following considerations: the enhanced accessibility of SVFs compared with ADSCs; the similar multipotent potential between SVFs and ADSCs; and the ease of obtaining SVFs using the laboratory facilities available at Hasanuddin University Medical Research Center (HUMRC), Hasanuddin University, Makassar, Indonesia, where the patients were treated. Because ADSCs only comprise $10 \%$ of SVFs, PRP can be used to stimulate the proliferation of both undifferentiated and differentiated stem cells to promote cell regeneration. ${ }^{7}$ This case series is reported in line with the Surgical Case Report Guidelines (SCARE Guidelines) published in $2020 .^{12}$

\section{Treatment}

Stromal Vascular Fraction Cells preparation

SVFs were prepared autologously from fat tissue that was collected from the abdominal area of each patient using liposuction. The liposuction procedure was performed by plastic surgeons and medical residents in an operating room at Wahidin Sudirohusodo Hospital, Makassar, Indonesia. A total of 200 grams of fat (Figure 1A) were obtained and cleaned with phosphate-buffered saline (PBS, Gibco-BRL, Grand Island, NY, USA). The fat was minced using scissors until a smooth consistency was obtained. The minced fat was transferred to a 50 -cc tube, $0.15 \%$ collagenase (Wako, Osaka, Japan) was added and the tube was incubated in a water bath shaker with shaking at $37^{\circ} \mathrm{C}$ for 30 minutes. Next, we added control medium, consisting of Dulbecco's modified Eagle medium (DMEM) (Gibco-BRL), containing 10\% autologous human serum (see below) and 1\% antibiotic-antimitotic (Sigma-Aldrich, St Louis, USA), to neutralize collagenase activity. The sample was centrifuged at 1,500 rpm for 5 minutes, and the pelleted cells were resuspended in sterile water (Figure 1B). Finally, the SVFs were counted using trypan blue staining (Gibco-BRL) and a Neubauer counting chamber. $^{13}$ 

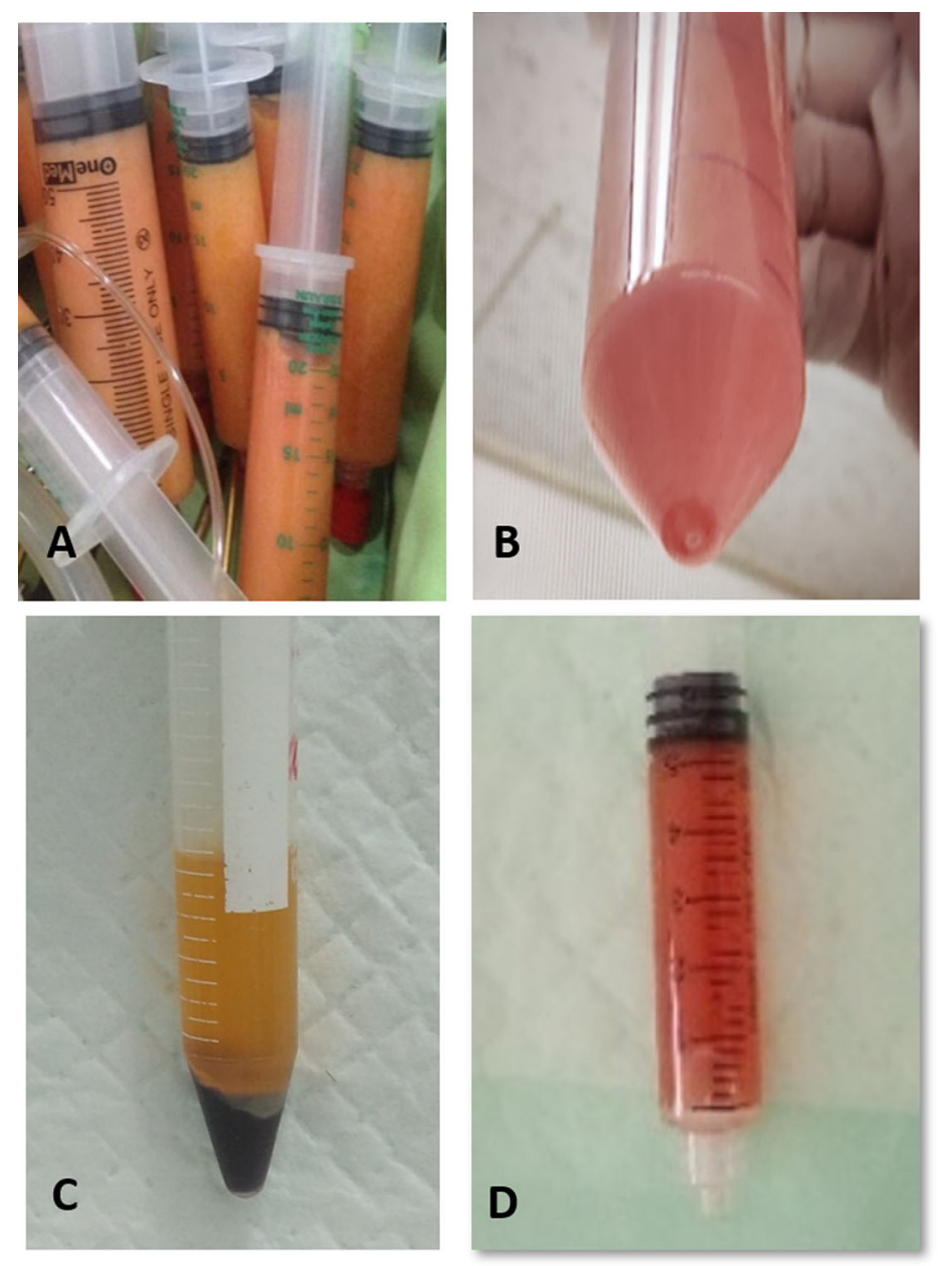

Figure 1. A) Lipoaspirate collected in an aspiration container. B) SVFs at the bottom of the tube. C) Supernatant plasma with the buffy coat was collected. D) SVFs pellets were mixed with 5 cc of autologous PRP. SVFs, stromal vascular fraction cells; PRP, platelet-rich plasma.

\section{Human serum preparation}

A total of 30cc autologous whole blood samples were obtained from the patients' median cubital vein using an 18-gauge needle and placed into a 50-cc tube. The tube was frozen at $4^{\circ} \mathrm{C}$. We centrifuged the blood samples at $2,500 \mathrm{rpm}$ for 10 minutes and transferred the serum to a 15 -cc tube. The serum was inactivated by heating to $56^{\circ} \mathrm{C}$ for 30 minutes. $^{14}$

\section{Platelet-rich plasma preparation}

A total of 20cc of blood was obtained from the patient's vein and collected in a tube containing ethylenediaminetetraacetic acid (EDTA). First, we centrifuged the tube for 10 minutes at 2,400 rpm $(450 \times g)$, to collect the supernatant plasma with the buffy coat (Figure 1C). The plasma with buffy coat was centrifuged again at 3,600 rpm $(850 \times g)$ for 15 minutes to concentrate the platelets. The top of an 18-gauge long cannula was guided to the bottom of the plasma to gently aspirate the infranatant plasma containing the buffy coat which was used to generate the PRP end product. ${ }^{15}$ PRPs were activated through the addition of $10 \% \mathrm{CaCl}_{2}$ (Merck, Germany) for a maximum of 10 minutes before use.

\section{Treatment procedure}

SVFs pellets containing $2 \times 10^{7}$ cells were added to $5 \mathrm{cc}$ PRP and mixed by pipetting (Figure 1D) before being transferred to a1-cc Eppendorf tube and activated with $0.5 \mathrm{cc} 10 \% \mathrm{CaCl}_{2}$ (Merck, Germany). A $100 \mu$ l volume containing the SVF and PRP mixture was injected into the patient's scalp at every $1 \mathrm{~cm}^{2}$ over the bald area. An application of antibiotic ointment was applied to the area after the treatment, and no hair supplement medication was applied afterward. The treatment procedures were performed by plastic surgeons. On day three after treatment, the patient's hair was washed with 
water and allowed to dry without the use of any other chemicals. After day 7, the patients were allowed to wash their hair as usual followed by air drying.

\section{Case series}

All of the cases described here were administered only one round of injections using the SVFs and PRP combination. Due to this being a standard treatment in our institution, we did not require ethical approval; all three patients signed informed consent forms to participate in the procedures, including liposuction, blood harvesting, injection therapy, and the use of their data and pictures for scientific publications.

\section{Case 1}

A 32-year-old Buginese man presented with hair thinning consistent with the typical pattern of androgenic alopecia, describing onset five years ago in the vertex and temporal areas (Figure 2A). A history of the same complaint was noted for the patient's father and brother. The patient was the only member of his family to experience baldness at a young age (30 years). The hair loss began to worsen one year prior to presentation. The patient is the third child of four sibling. The patient had no history of alcohol consumption or cigarette use and no history of cardiac disease, diabetes mellitus, or any other degenerative disease. The patient tried several hair tonic treatments (not prescribed) to resolve the problem, with no satisfactory results.

The patient was diagnosed with androgenic alopecia Norwood Hamilton type IIIa of the vertex, based on the clinical appearance. ${ }^{16}$ The patient was treated with the local injection of combined PRP and SVFs. At one month of follow-up, the patient displayed thick and substantial hair growth. According to the patient's self-report, additional hair loss was minimal (Figure 2B).

\section{Case 2}

A healthy 43-year-old Javanese man suffered from hair thinning in the vertex and temporal areas of the scalp that started eight years prior to presentation. No history of the same complaint was noted for his father or his three brothers, but the patient's uncle suffered from alopecia. The patient had no history of alcohol consumption, but the patient was a previous smoker who had stopped smoking five years prior to presentation. The patient had visited a beauty clinic to treat the hair loss, but this treatment showed no results. The beauty clinic provided the patient with a shampoo, a hair growth tonic, and oral minoxidil therapy at daily dose of $2.5 \mathrm{mg}$ for six weeks. The patient stopped treatment after six weeks because hair growth was apparent on the hands, feet, chest, and chin but not the scalp, and the patient continued to experience hair thinning and hair loss on the scalp.

The patient was diagnosed with androgenic alopecia Norwood Hamilton type IIIa of the vertex, based on clinical appearance (Figure 3A). ${ }^{16}$ The patient was treated with the local injection of combined PRP and SVFs. After one month

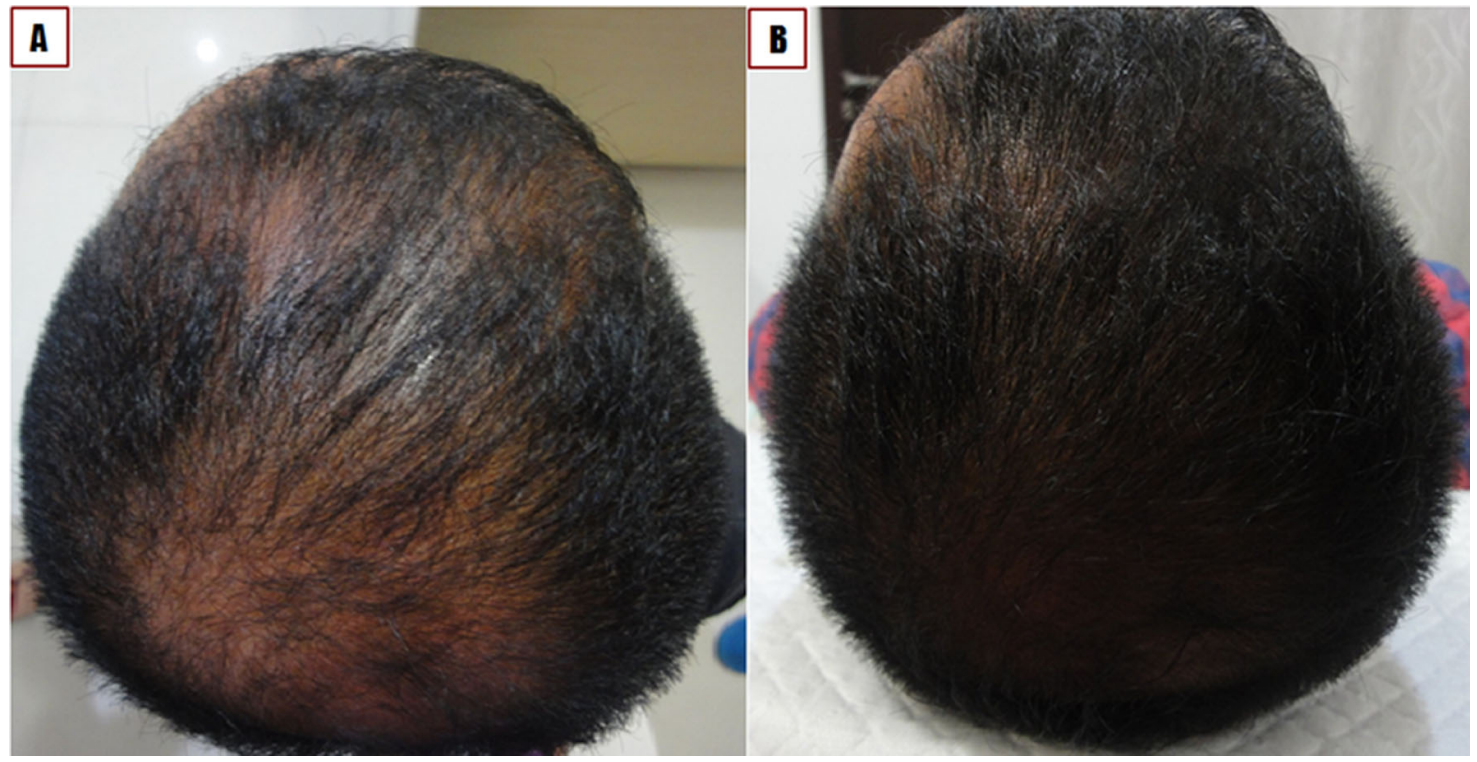

Figure 2. Case 1: a 32-year-old male with type IIIa alopecia. A) Before treatment. B) One month after treatment. 


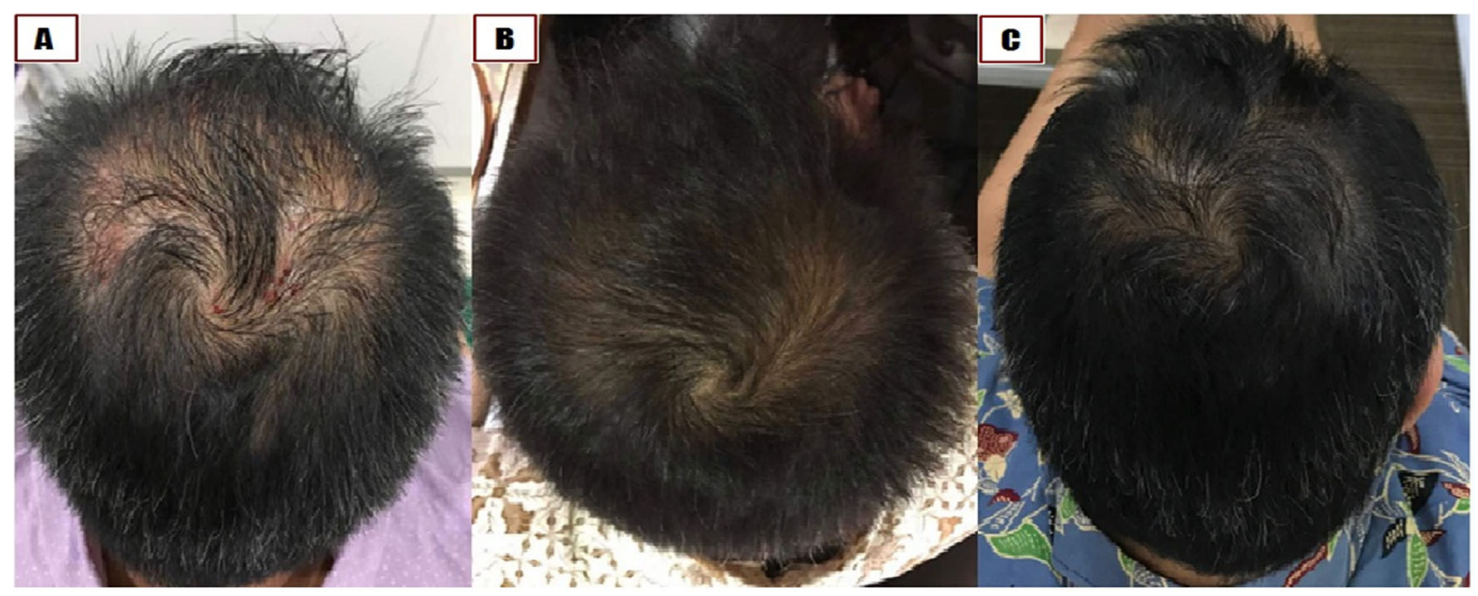

Figure 3. Case 2: a 43-year-old male with type IIIa alopecia. A) Before treatment. B) One month after treatment. C) Three months after treatment.

of follow-up, the patient's hair was beginning to grow, with a denser hair follicle (Figure 3B). Three months after the treatment, the hair grew significantly, although the hair at the injection area grew darker than hair that grew in other areas (Figure 3C).

\section{Case 3}

A 65-year-old Buginese man suffered from thinning hair with onset 30 years ago in the vertex, temporal, and occipital areas of the scalp (Figure 4A). No similar issue was reported in his family. The patient never consumed any alcohol or smoked cigarettes. The patient maintained a healthy lifestyle and engaged in regular cycling in the mornings. The patient had no history of hypertension, diabetes mellitus, cardiac disease, or any other degenerative disease, and the patient reported never using any medications for hair loss.

The patient was diagnosed with androgenic alopecia, Norwood Hamilton type IVa in the vertex, temporal, and occipital areas based on clinical appearance. The patient was treated with the local injection of combined PRP and SVFs in bald areas of the scalp. After one month of follow up, new hair started to grow densely. After three months of follow-up, the patient showed increased hair thickness on each strand, denser hair, and the hair-pull test revealed that the hair remained intact (Figure 4B and 4C).

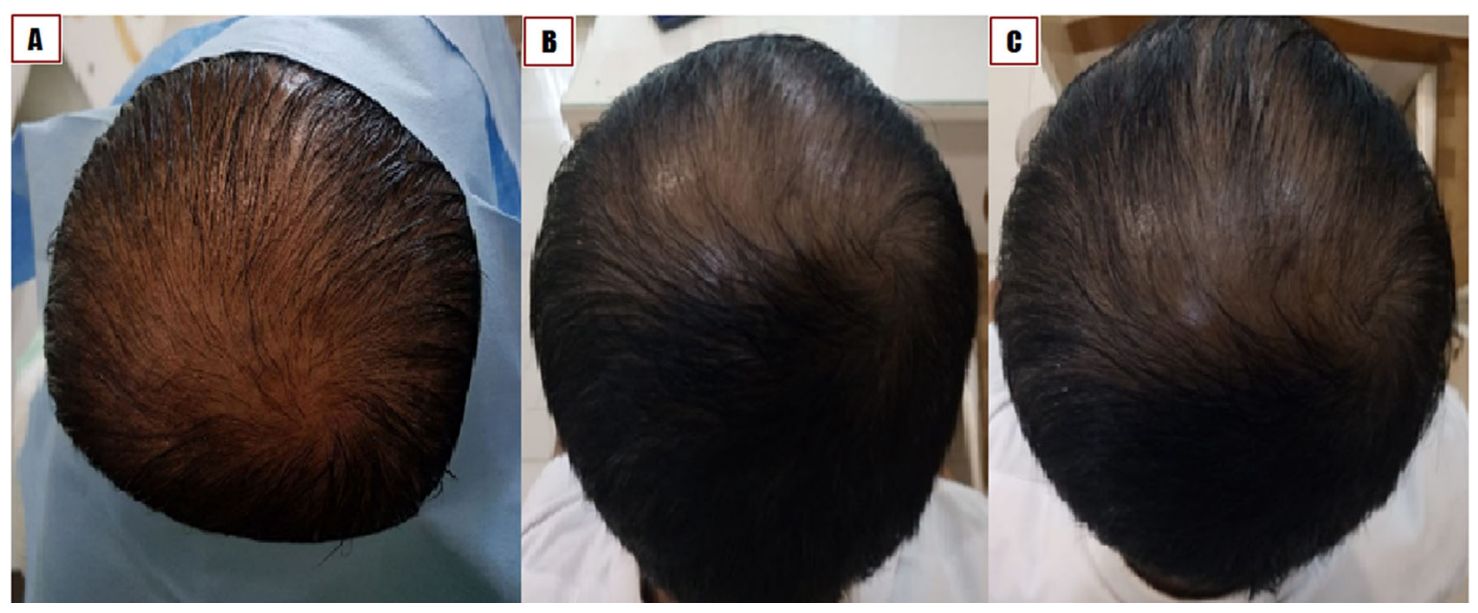

Figure 4. Case 3: a 65-year-old male with type IVa alopecia. A) Before treatment. B) One month after treatment; C) Two months after treatment. 


\section{Discussion}

Typical hair growth cycles are divided into three phases: anagen (active phase of hair follicle growth which lasts approximately 2-6 years); catagen (transition phase, lasting approximately 2-3 weeks); and telogen resting phase (lasting approximately three months). Hair growth patterns change during androgenic alopecia, associated with a shorter anagen phase and a prolonged telogen phase, which changes the anagen to telogen ratio from 12:1 to 5:1, resulting in more hair follicles in the telogen phase at any given time. Hair loss is promoted under these conditions eventually resulting in the development of baldness. ${ }^{17}$

Androgenic alopecia treatment remains challenging for many doctors. PRP has been widely used to treat androgenic alopecia, but several PRP injection sessions are required for effective treatment and more severe baldness requires more PRP injection sessions, with shorter intervals between sessions to prevent hair loss. The patient's age can also influence the necessity for PRP injection repetitions and may affect the growth factors produced by PRP.

SVFs are a mix of heterogeneous cells that consist of ADSCs, hematopoietic stem cells, progenitor cells, pericytes, and other differentiated cells (such as fibroblasts, macrophages, endothelial cells [ECs], and preadipocytes). SVFs contain essential factors for angiogenesis, including endothelial progenitor cells (EPCs) and ECs. Approximately $7 \%$ to $30 \%$ of EPCs and ECs secrete growth factors, including VEGF, PDGF subunit B (PDGF-BB), and bFGF. The secretion of the growth factors from SVFs, such as VEGF, HGF, IGF-1, and TGF- $\beta 1$, can directly contribute to angiogenesis through the paracrine effect. ${ }^{18}$

According to Trueb, androgen receptors and the microinflammation of the hair follicle can cause androgenic alopecia. The production of reactive oxygen species and reactive nitrogen species due to chemical stress can induce pro-inflammatory cytokine secretion, resulting in the development of a microinflammatory environment at the hair follicle. Inflammation can affect the hair follicle and the surrounding area, resulting in the development of perifollicular fibrosis, hair stem cell apoptosis, the shrinkage of the hair follicle, and the thinning of the scalp. The prolonged scalp thinning process makes the skin appear shiny. DHT reduces the production of IGF-1 and stem cell factor, resulting in hair stem cell apoptosis, vellus hair transformation, and permanent hair loss. ${ }^{4}$ The combination of PRP and SVFs affects all cycles of hair growth. An experiment demonstrated that SVFs had regenerative abilities, reduced the secretion of pro-inflammatory cytokines (such as Interleukin [IL-6] and tumor necrosis factor [TNF- $\alpha$ ]), increased the production of the anti-inflammatory cytokine IL-10, and increased the proportion of the M2 macrophage phenotype. ${ }^{19}$ Treatment with SVFs has been shown to eliminate the microinflammatory process at the hair follicle. The thickening of the scalp's hair may be caused by the differentiation of the ADSCs that can be found in SVFs. ADSCs have anti-fibrotic abilities because they can reduce the production of the fibrotic agent TGF- $\beta 1$, reducing permanent hair loss by improving perifollicular fibrosis. ${ }^{20}$ The IGF- 1 found in PRP plays a vital regulatory role in hair growth cycles and hair cell differentiation and inhibits the apoptosis pathway involved in hair follicle regeneration. In this case series, the treatment applied to all three patients resulted in hair that grew denser, with reduced hair loss during the hair pull test assessment. The new hair grew darker than normal hair, which may be due to the effects on melanocytes, which are involved in hair pigmentation, induced by the local injection of the PRP and SVF combination. ${ }^{4}$

SVFs stimulate the angiogenesis process increasing the blood supply to the hair follicle by inducing VEGF secretion. The addition of PRP to SVFs, improves the angiogenesis process, resulting in denser hair growth and larger hair follicles.

In our patients, the therapeutic mixture was injected directly into the scalp of the bald area, allowing the components to act immediately at the alopecia site. We minimized the use of xenogeneic-based product consumption and prevented the transmission of diseases from animals or the possibility of anaphylactic reactions by replacing the fetal bovine serum in the controlled medium with autologous human serum. The injections of the PRP and SVF combination must be performed in less than 10 minutes because the combination can transform into a gel if delayed for longer than 10 minutes, which can complicate the injection process.

The patient's age and alopecia duration could affect the therapeutic efficacy. In our patients, the younger patients had denser and thicker hair growth. In Case 1, the effects of the injection therapy were visible within 1 month, which may be due to the patient's young age (32 years), and the duration of alopecia which only 5 years, unlike the conditions associated with Case 3 . Although the hair growth in case 1 and 3 both produced satisfactory results that were almost similar to normal hair growth, Case 1 demonstrated a better effect than Case 3, which may be due to the older age (65 years) and longer disease duration (30 years) associated with Case 3. In addition, the production of growth factors and the multipotent abilities of ADSCs derived from Case 3 may have been diminished compared with those for Case 1 due to the patient's older age. 
We hope that the combined use of PRP and SVFs in alopecia can reduce the necessity for repeated injections and reduced the frequency of treatments to just one injection. This study requires more extended and continuous observations to determine the long-term therapeutic effects, which appear to promote the anagen phase of hair follicles and reduce the telogen phase duration.

\section{Conclusion}

The combination treatment with PRP and SVFs appeared to affect all cycles of hair growth. SVFs are multipotent cells that has the effects of antioxidant, anti-inflammatory, and anti-fibrotic. SVFs regenerate cells and secrete essential growth factors that are necessary for angiogenesis in the scalp. The combined effects induced by SVFs and PRP treatments provide excellent promise for the treatment of androgenic alopecia. Younger patients with shorter alopecia durations appeared to display better results. The use of all autologous materials is promising for the treatment of other types of alopecia, including alopecia areata.

\section{Consent}

Written informed consent for publication of their clinical details and/or clinical images was obtained from the patients.

\section{Data availability}

All data underlying the results are available as part of the article and no additional source data are required.

1. Meidan VM, Touitou E: Treatments for androgenetic alopecia and alopecia areata: current options and future prospects. Drugs. 2001; 61(1): 53-69.

PubMed Abstract | Publisher Full Text

2. Nyholt DR: Basis of male pattern baldness. Invest Dermatol. 2003; 121(6): 1561-1564.

PubMed Abstract | Publisher Full Text

3. Rathnayake D, Sinclair R: Male androgenetic alopecia. Expert Opin Pharmacother. 2010; 11(8): 1295-1304. PubMed Abstract | Publisher Full Text

4. Trüeb R: Molecular mechanisms of androgenetic alopecia. Exp Gerontol. 2002; 37: 981-990.

PubMed Abstract | Publisher Full Text

5. Smith MA, Wells RS: Male-type alopecia, alopecia areata, and normal hair in women; Family Histories. Arch Dermatol. 1964; 89: 95-98. Epub 1964/01/01.

PubMed Abstract | Publisher Full Text

6. Eppley BL, Pietrzak WS, Blanton M: Platelet-rich plasma: a review of biology and applications in plastic surgery. Plast Reconstr. Surg. 2006; 118: 147e-159e.

PubMed Abstract | Publisher Full Text

7. Hausman GJ, Richardson RL: Adipose tissue angiogenesis1,2. J. Anim. Sci. 2004; 82: 925-934.

PubMed Abstract | Publisher Full Text

8. Zuk $P, Z$ hu $M$, Ashjian $P$, et al.: Human adipose tissue is a source of multipotent stem cells. Mol Biol Cell. 2002; 13(12) 4279-4295.

PubMed Abstract | Publisher Full Text | Free Full Text

9. Choi J, Minn KW, Chang H: The efficacy and safety of platelet-rich plasma and adipose-derived stem cells: an update. Arch Plast Surg. 2012; 39: 585-592.

PubMed Abstract | Publisher Full Text | Free Full Text

10. Darinskas A, Paskevicius M, Apanavicius G, et al.: Stromal vascular fraction cells for the treatment. 2017.

11. Rigotti G, Marchi A, Sbarbati A: Adipose-derived mesenchymal stem cells: past, present, and future. Aesthetic Plast Surg. 2009; PubMed Abstract | Publisher Full Text
12. Agha RA, Franchi T, Sohrabi C, et al.: The SCARE $\mathbf{2 0 2 0}$ Guideline: Updating Consensus Surgical CAse REport (SCARE) Guidelines. Int J Surg. 2020. PubMed Abstract | Publisher Full Text

13. Josh $\mathrm{F}$, Kobe $\mathrm{K}$, Tobita $\mathrm{M}$, et al.: Accelerated and safe proliferation of human adipose-derived stem cells in medium supplemented with human serum. J Nippon Med Sch. 2012; 79(6): 444-452. PubMed Abstract | Publisher Full Text

14. Josh F, Tobita M, Tanaka R, et al.: Concentration of PDGF AB, BB and TGF-B1 as valuable human serum parameters in adiposederived stem cells proliferation. J Nippon Med Sch. 2013; 80(2): 140-147. PubMed Abstract | Publisher Full Text

15. Tajima S, Tobita $M$, Orbay $H$, et al.: Direct and indirect effects of a combination of adipose-derived stem cells and platelet-rich plasma on bone regeneration. Tissue Eng Part A. 2014; 0(0): 1-11. PubMed Abstract | Publisher Full Text

16. Gupta M, Mysore V: Classifications of Patterned Hair Loss: A Review.J Cutan Aesthet Surg. 2016; 9(1): 1-10. PubMed Abstract | Publisher Full Text | Free Full Text

17. Chin Gan D, Sinclair R: Androgenetic alopecia. Third Edition: Men's Health; 2009; 352-367. Publisher Full Text

18. Gentile P, Scioli MG, Bielli A, et al.: Concise Review: The Use of Adipose-Derived Stromal Vascular Fraction Cells and Platelet Rich Plasma in Regenerative Plastic Surgery. Stem Cells. 2017; 35 : 117-134.

PubMed Abstract | Publisher Full Text

19. Kotani T, Masutani R, Suzuka T, et al.: Anti-inflammatory and antifibrotic effects of intravenous adipose-derived stem cell transplantation in a mouse model of bleomycin-induced interstitial pneumonia. Sci Rep. 2017; 7: 1-10. PubMed Abstract | Publisher Full Text | Free Full Text

20. Borovikova AA, Ziegler ME, Banyard DE, et al.: Adipose-Derived tissue in the Treatment of Dermal Fibrosis: Antifibrotic Effects of Adipose-Derived Stem Cells (Review). Ann Plast Surg. 2018 Mar; 80(3): 297-307.

PubMed Abstract | Publisher Full Text 


\section{Open Peer Review}

\section{Current Peer Review Status: ? ?}

\section{Version 1}

Reviewer Report 13 July 2021

https://doi.org/10.5256/f1000research.56025.r86914

(C) 2021 Sukmawati D. This is an open access peer review report distributed under the terms of the Creative Commons Attribution License, which permits unrestricted use, distribution, and reproduction in any medium, provided the original work is properly cited.

\section{Dewi Sukmawati}

Department of Histology, Faculty of Medicine, Universitas Indonesia, Jakarta, Indonesia

Overall, this case series is interesting and will potentially be a benefit for patients with alopecia. The authors clearly described the advantages of each component, the stromal vascular fraction cells (SVFs) and platelet-rich plasma (PRP), for alopecia, and claimed their novelty by combining both components, which gives the important result.

Although it showed promise, however, the current supporting data were the pictures that the authors only descriptively explained. Thus, to provide a reliable result, it is suggested to the authors to add the details to support the countable results. This may include:

1. The objective measures, such as the hair density, hair diameter, or hair shaft thickness of the terminal follicle.

2. The subjective assessment of hair growth, such as patient's self-assessment using a questionnaire or scoring.

3. A similar observation time. The three cases were not all observed within three months (Case 1 = one month, Case 2 = three months, and Case $3=2$ months). The authors should recheck the inconsistency between the text and the figure's caption.

A sufficiently long duration of follow-up should also be done to facilitate accurate assessment of clinical improvement in measures such as hair counts/density, hair thickness, patient's subjective assessments, and overall alopecia, as well as evidence of relapse. Several studies perform further follow-up, such as within 6-12 months.

In addition, since there is no control for SVFs or PRP only, the authors should further explain the possible mechanism, whether the beneficial clinical effect was due to the accumulative effect, potentiates or synergistic effect of both SVFs and PRP.

Is the background of the cases' history and progression described in sufficient detail? Yes 
Are enough details provided of any physical examination and diagnostic tests, treatment given and outcomes?

Partly

Is sufficient discussion included of the importance of the findings and their relevance to future understanding of disease processes, diagnosis or treatment?

Yes

Is the conclusion balanced and justified on the basis of the findings?

Yes

Competing Interests: No competing interests were disclosed.

Reviewer Expertise: Histology, Stem Cells, Angiogenesis, Endothelial Progenitor Cells

I confirm that I have read this submission and believe that I have an appropriate level of expertise to confirm that it is of an acceptable scientific standard, however I have significant reservations, as outlined above.

Reviewer Report 04 June 2021

https://doi.org/10.5256/f1000research.56025.r86430

(C) 2021 Mizuno H. This is an open access peer review report distributed under the terms of the Creative Commons Attribution License, which permits unrestricted use, distribution, and reproduction in any medium, provided the original work is properly cited.

Hiroshi Mizuno

Department of Plastic and Reconstructive Surgery, Juntendo University School of Medicine, Tokyo, Japan

The authors described the positive effect of the combination therapy with autologous stromal vascular fraction cells (SVFs) and platelet-rich plasma (PRP) for androgenic alopecia, which is understandable. However, the follow-up periods of all three cases are less than three months. The authors are requested to explain any speculation about the long-term results.

In addition, the authors are requested to explain whether such clinical results were obtained due to merely cumulative effect or synergistic effect of SVFs and PRP.

As the authors described, the combination use of both SVFs and PRP for androgenic alopecia may not be published elsewhere, which is of major significance.

Is the background of the cases' history and progression described in sufficient detail? Yes

Are enough details provided of any physical examination and diagnostic tests, treatment 
given and outcomes?

Yes

Is sufficient discussion included of the importance of the findings and their relevance to future understanding of disease processes, diagnosis or treatment?

Partly

Is the conclusion balanced and justified on the basis of the findings?

Yes

Competing Interests: No competing interests were disclosed.

Reviewer Expertise: Adipose-derived stem cells, stromal vascular fraction, wound healing

I confirm that I have read this submission and believe that I have an appropriate level of expertise to confirm that it is of an acceptable scientific standard, however I have significant reservations, as outlined above.

The benefits of publishing with F1000Research:

- Your article is published within days, with no editorial bias

- You can publish traditional articles, null/negative results, case reports, data notes and more

- The peer review process is transparent and collaborative

- Your article is indexed in PubMed after passing peer review

- Dedicated customer support at every stage

For pre-submission enquiries, contact research@f1000.com

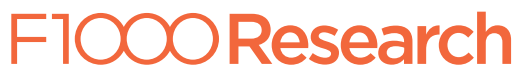

